

\section{UM BRASILEIRO EM TERRAS COLONIAIS PORTUGUESAS}

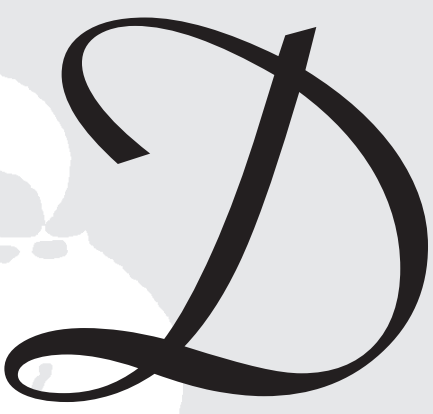

esde os começos da Ditadura Militar, e logo depois com o "Estado Novo" salazarista dos anos 30-com o Acto Colonial desse ano, posteriormente incluído no texto da Constituição de 1933 -, que o discurso colonialista português se baseava essencialmente na ideia de um pretenso direito imperial de conquista, exploração,

O Messias desiludiunos. [...] não

devemos tomar como traduzindo o Cabo

Verde caboverdiano certas conclusões a que implícita e explicitamente chegou Gilberto Freyre no seu livro Aventura e Rotina" (Baltasar Lopes, Cabo Verde Visto por Gilberto Freire, Praia, 1956).

\section{“ Diz-me [Gilberto}

Freyre] que concorda inteiramente com

a nossa política africana" (20-XI1962) (Franco Nogueira, Um Político Confessa-se. Diário, 1960-68, Lisboa, (986).

\section{" $[\ldots]$ cette imposture} voilée qu'est le lusotropicalismo" (Mário Pinto de Andrade, Présence Africaine, no 4, outubro/ novembro de 1955). missionação católica e "civilização" (I). Desta fase inicial, até finais da década de 40 , foi sobretudo Henrique Galvão (1895-1970) o grande teorizador da nossa ideologia africanista, e da qual foi expoente a Exposição Colonial do Porto, em 1934, secundada pelo mapa em que se afirmava que "Portugal não é um país pequeno".

Em 1947, caído em desgraça o azougado romancista e teorizador colonial, autor do verdadeiro manifesto de reactivação da missão colonialista portuguesa que fora o seu livro Velo de Oiro (I a ed., 193I, reed. em em 1933 e 1936), um outro ciclo do pensamento justificativo do nosso colonialismo se seguiria, em larga medida adaptado ao novo condicionalismo mundial posterior ao fim da Segunda Guerra. E assim, com o começo da década de 50, na altura em que os ventos das independências africanas (e asiáticas) começavam a estimular os movimentos de libertação das colónias europeias em África (e na Ásia), recorreu a Ditadura portuguesa a uma formulação ideológica mais sofisticada, agora com o tão útil e oportuno suporte achado na colaboração prestigiante, activa e politicamente assumida por parte do sociólogo Gilberto Freyre ( 1900 87), cuja teorização lusotropicalista se iniciara com as suas grandes obras do anos 30, dedicadas a explicar a formação do Brasil em perspectivas inovadoras, rompendo com os parâmetros naturalistas ou marxistas, tanto anteriores como posteriores - obra de que Casa Grande e Senzala (1933) seria a pedra angular.

Recorrendo ao grande mestre heterodoxo pernambucano, o "Estado Novo" salazarista socorria-se, dest'arte, de uma ideologia legitimadora do seu colonialismo, pretensamente imune de qualquer forma de racismo, baseado na argumentação oportuna usada pelo
Recordemos algunstextos onde a ideia estadonovista do "Império" era explicada : O Pensamento do Ministro das Colónias, Dr. Armindo Monteiro (Lisboa, Edições SPN, 1934, 31 pp.l: João Ameal, Decálogo do Estado Novo (Lisboa, Edições SPN 1934, 94 pp; maxime pp. 85 6): O Estado Novo. Princípios e Realizações (2ed., Lisboa SPN, 106 pp.; maxime pp. 67-81); O Império (Lisboa s.d., 1938, 55 pp.|: Henrique Galvão, O Império (Lisboa SNI, s.d., 31 pp.l. 
2 Veja-se o recente estudo de José Carlos Reis, "Anos 1930: Gi berto Freyre. O re-elogio da Colonização Portuguesa", in Pós-História (Revista de pós-graduacão em História Assis vol. 6,1998 , Univ. Estadud Paulista, pp. 33-67). Outros exemplos de recente bibliografia passiva em torno de G. Freyre: Fernando de Mello Freyre, Brasileiridade, Recife, Massangana, Fundação José Nabuco, 1992, 189 pp. Manuel Correia de Andrade org.l, Gilberto Freyre. Pensa mento e Acção Recife Massangana, Fundação J Nabuco, 1995, 165 pp Vamireh Chacon, Gilberto Freyre. Uma Biografia Intelectual, Recife/São Paulo Massangana/Companhia Ed tora Nacional, 1993, 312 pp. Edson Nery da Fonseca lorg. Sobrados e Mucambos. Entendimento e Interpretação, Recife, Massangana, 1996, 160 pp.; Sebastião Vila Nova, So ciologias \& Pós-Sociologia em Gilberto Freyre, Recife, Massangana, 1995, 137pp. Revista Ciência e Trópico, vol. 20, no 2, julho-dezembro de 1992; Diogo de Melo Meneses, Gilberto Freyre /pref de Monteiro Lobato), Rio de aneiro, CEB, 1944, 297 pp. Gilberto Freyre lantologia org por Edilberto Coutinhol, Rio do aneiro, Agir, 1994, 124 pp.l.

3 Franco Nogueira, Um Político Confessa-se. Diário: 1960 1968 3a ed Porto Civilizo ção, 1987, p. 47|

4 Recordem-se as obras de Adriano Moreira, Política Ultromarina lLisboa. Ministério do Ultramar, Junta de Investigaçõe do Ultramar, 1956, 343 pp. e Batalha da Esperancal"Polltica de Integração", pp. 101 19, Lisboa, Edições Panorama 1962, 221 pp.); Orlando Ribeiro, Aspectos e Problemas da Expansão Portuguesa (Lisboa Fundação da Casa de Braganca, 1955): Almerindo Lessa, Jornal (1947-1957). Um Médico, o seu Mundo e os seus Fantasmas (Lisboa, Editoria Medicis, 1958, 238 pp. Meridianos Brasileiros (Lisboa Junta de Inv. do ultramar, 389 pp.): Laços por Atar (Lisboo, 1964 separata da revista $S$ mana Médica, de 17-V-1964 No Tempo do meu Espaço (Lis ocademia Internaciona de Cultura Portuguesa, 1995 459 pp.l; Jorge Borges de Macedo, "O Luso-Tropicalismo de Gilberto Freire - Metodologia, Prática e Resultados" |re vista ICALP, n- 15, 1989, pp. 32-56): losé Júlio Gonçalves, Gilberto Freyre - O Sociólogo e Teorizador do Lusotrop sociólogo brasileiro para explicar a génese da sociedade do Brasil, e que passaria a ser formulada em termos de alibi para a recusa portuguesa em descolonizar os seus territórios coloniais em África (Cabo Verde, São Tomé e Príncipe, Guiné-Bissau, Angola e Moçambique) e na Ásia (Índia Portuguesa, Timor). Desde então, apropriando-se tanto do seu nome como da sua obra, o governo de Lisboa explorou a fundo a complacente cumplicidade de Gilberto Freyre, sobretudo a partir de 1951-52 - altura em que o pernambucano aceitou o convite do ministro das Colónias de Portugal, Sarmento Rodrigues (1899-1979), para visitar as colónias portuguesas da Guiné, Cabo Verde, Angola, Moçambique e Índia (Freyre não visitaria Timor) -, inclusive editando em várias línguas os textos escritos ad hoc pelo pensador recifense, como sucedeu com a obra $O$ Luso e o Trópico (Lisboa, 1961) ou Aventura e Rotina (ed. no Brasil: 1953; ed. portug.: Lisboa, 1954), sendo o primeiro estampado já depois de começado, em 1961, o ciclo de guerras de libertação das colónias lusas, obras que, curiosamente, nem sempre tiveram edição no Brasil - lembremos ainda outro título editado em Portugal: Integração Portuguesa nos Trópicos (Lisboa, 1954) -, sendo portanto, em geral, desconhecidas da bibliografia brasileira mais recente em torno do hoje tão relido quanto controverso (e heterodoxo) sociólogo-historiador de Santo António de Apipucos (2).

A utilização político-propagandística do pensamento de Freyre fez-se, sublinhe-se, com total cumplicidade do interessado, cuja avidez de homenagens e honrarias oficiais Franco Nogueira não se esqueceria de averbar no seu diário de ministro dos $\mathrm{Ne}$ gócios Estrangeiros no período mais duro das guerras africanas e da tormenta internacional contra a nossa política colonial. Leiamos o depoimento que nos deixou o supremo responsável pela diplomacia lusa durante a maior parte dos anos de guerras coloniais: "Almoço no Ritz em honra de Gilberto Freyre. Pareceu ávido de honrarias, homenagens, elogios de 5 em 5 minutos. Diz-me que concorda inteiramente com a nossa política africana" (3).

Foi isto escrito em 20 de novembro de 1962, com a guerra angolana em pleno desenvolvimento. O presente estudo pretende tão só recordar algumas das respostas que ao pernambucano deram, tanto antes de começarem as guerras nas nossas colónias africanas como na altura em que elas já aí lavravam alguns dos intelectuais e dirigentes políticos nacionalistas africanos, ora simples críticos das implicações lusotropicalistas, ora dirigentes políticos em luta contra o colonialismo português. Iremos resumir o processo, fundamentalmente, a duas tomadas de posição crítica, a do caboverdiano Baltasar Lopes (1907-89), em 1956, e do angolano Mário Pinto de Andrade (1928-90), em 1955. Referiremos ainda a crítica ao lusotropicalismo pelo dirigente da guerrilha da Guiné-Bissau, Amílcar Cabral (1924-73), em 1968.

\section{O LUSOTROPICALISMO COMO UMA "IMPOSTURA VELADA": A CRITIICA DE MÁRIO PINTO DE ANDRADE}

A noção, ou melhor, o mito de que Portugal não seria racista nem colonizaria porque era, desde a sua mais íntima natureza, multirracial e pluricontinental, aparecendo portanto como uma nação africana também, estaria presente nos principais discursos dos dirigentes da Ditadura salazarista, tanto nos discursos do próprio Salazar como em Franco Nogueira, sem esquecer académicos ou ideólogos como Adriano Moreira, Orlando Ribeiro, Almerindo Lessa, J. J. Gonçalves, Jorge Dias, etc. (4) e no seu complemento marcelista (196874), tendo sido naturalmente repudiada pelos líderes e pensadores dos movimentos de emancipação das colónias lusas, tais como os escritores e dirigentes políticos acabados de mencionar. $\mathrm{O}$ anti-lusotropicalismo destes dirigentes dos movimentos de libertação africana comprova assim que as ideias pró-ditatoriais e colonialistas 
(portuguesas), ou o seu alibi legitimador, colhidas em G. Freyre, repugnaram aos povos que lutavam por se libertarem do “imperialismo" luso, ainda que este cosmeticamente se maquilhasse de coloridas fantasias extrapoladas das teorias freyrianas acerca da formação do mundo brasileiro, teorias que talvez nem mesmo para explicar a génese da comunidade miscigenada do Brasil colonial fossem inteiramente acertadas, sociedade que o autor de Casa Grande e Senzala defendia ter sido um harmonioso equilíbrio de antagonismos, produzindo uma sociedade que foi uma das mais democráticas, flexíveis e plásticas, por ter logrado equilibrar antagonismos dificilmente superáveis, tais como os que se polarizavam entre culturas europeia, africana e indígena (as três raças formativas do Brasil: o português, o índio e o negro), economia agrária e pastoril, entre fazendeiro e jesuíta, bandeirante e senhor de engenho, sem esquecer o antagonismo maior, entre o senhor e o escravo negro; de tudo isto teria nascido, escrevera Freyre nas suas grandes obras dos anos 30, uma sociedade marcada pela tolerância social e religiosa, a democracia social brasileira, em que todos os antagonismos de base teriam sido finalmente superados pela mobilidade social vertical, pela miscigenação social e rácica melhor, pela ausência de racismo do português -, pela geografia sem obstáculos e ainda pelo "cristianismo lírico".

Nabase de todo este edifício lusotropical estava, portanto, o português colonizador, avesso ao racismo, eroticamente vocacionado a ligar-se sem quaisquer preconceitos racistas com índias e negras, o português reinol que era já, ele mesmo, produto de miscigenações de judeus, árabes e cristãos... Este português, vitoriosamente aclimatado aos trópicos, criara a pujante cultura e civilização do Brasil, criação para a qual Freyre vinha há muito pedindo a fundação de uma nova ciência explicativa do fenómeno sem par na história geral das civilizações - Toynbee, por exemplo, esquecera-se de mencionar o nosso grande êxito ecológico-histórico nos trópicos de Vera Cruz -, a luso-tropicologia (sic) (5).
Cremos que a primeira crítica explícita e politicamente assumida ao lusotropicalismo freyriano surgiu nas páginas da revista parisiense Présence Africaine, em 1955, sob o pseudónimo de Buanga Fele: intitulava-se "Qu'est-ce que le 'lusotropicalismo'?" e saiu no no 4 (outubro/novembro de 1955) dessa importante revista teórica do nacionalismo africano dessa década e da seguinte (6). Nascido em 1928 no Galungo Alto (Angola), o seu autor começara por frequentar o seminário em Luanda, mas acabara por escolher os estudos universitários, embarcando para Lisboa, a fim de ali tirar o curso de Letras na Faculdade de Letras de Lisboa, ao mesmo tempo que teria ocasião de conviver, na altura ou posteriormente, tanto intelectual como politicamente, com alguns intelectuais e políticos da africanidade: Agostinho Neto, Eduardo Mondlane, Amílcar Cabral, Francisco José Tenreiro, etc. Em 1953 organizava o Caderno de Poesia Negra de Expressão Portuguesa. Fundara, dois anos antes, o Centro de Estudos Africanos (1951). Em 1954 partia para Paris e, em 1955, já como redactor da Présence Africaine, seria um dos organizadores do I Congresso dos Escritores e Artistas Negros. Em 1958, juntamente com o poeta Viriato da Cruz - que havia de morrer exilado, na China -, representou Angola na I Conferência de Escritores Afro-Asiáticos, em Tachkent. Com a criação do MPLA, em 1960, assumiu a sua presidência, cargo que ocupou até 1962. Em 1971-72, integrou o Comité de Coordenação Político-Militar do MPLA na Frente Leste. Em 1974, juntamente com o seu irmão Joaquim Pinto de Andrade, assumiu-se como um dos dirigentes de uma corrente de intelectuais nacionalistas que se opunham, no MPLA, à liderança de Agostinho Neto, tendência conhecida pela designação de "Revolta Activa". Exilou-se na Guiné-Bissau após a independência de Angola (1975). Postumamente, publicou-se o seu livro Origens do Nacionalismo Africano (Lisboa, 1977). Faleceu em 1990. Foi portanto este o intelectual angolano que, pela primeira vez, tomou a iniciativa de denunciar no calismo Iseparata da Acade mia Internacional da Cultura Portuguesa, no 3,1967 pp. 49-72); Jorge Dias (1907. 1973), O Carácter Naciona Português na Presente Conjuntura (Lisboa, separata da Aca demia Internacional de Cultu ra Portuguesa, 1968).

5 G. Freyre, O Luso e o Trópico, Lisboa, Comissão Executiva para a Comemoração do $V$ Centenário da Morte de Intante Dom Henrique, 1961, p. 51

6 Buanga Fele (i.e., Mário Pinto de Andrade), "Qu'est-ce que le "lusotropicalismo'?" Présence Africaine, Paris, $n^{\circ}-4$, outubro/ novembro de 1955, pp. 24-35 
7 M. P. de Andrade, "Qu'est-ce que le 'lusotropicalismo'?", op cit., p. 25.

8 Daniel F. Malan (1874-1959 educado na África do Sul e em Utreque, pregador da Igreja Reformada holandesa, abandonou a carreira eclesiástica enveredou pela vida políitica en Africa, editando um jornal nacionalista e entrando, em 1918, para o Parlamento suafricano, participando num governo Trabalhista/Nacionalista em 1924. Foi um dos que favoreceu a adopção do afrikaans como língua oficial da Africa do Sul, liderando a oposição de 1934 a 1939, tor nando-se primeiro ministro e ministro dos Negócios estrange ros de 1940 a 1948, coubthe a principal responsabilidade pela política que ticaria conhecida como apartheid favorecendo a constituição de zonas raciais diferenciadas e $\mathrm{cr}^{-}$ ando uma legislação segregacionista que valeria à África do Sul a hostilidade doméstica e internacional. Afastou-se em 1954. Duro austero estrudioso, o dr. Malan foi verdadeiro Moisés dos Boers friamente convicto da supremacia branca no sul de África da missão afrikaner em África. Sucederam-the, em 1958, Verwoerd, em 1966, Vorster, em 1978, Botha, e, em 1989 de Klerk, que abandonaria nalmente o apartheidem 1991.

9 M. P. Andrade, ibidem, loc. cit

10 ldem, ibidem, pp. 25-6

$11 \mathrm{ldem}$, ibidem, p. 26. lusotropicalisnmo freyriano o insustentável alibi do colonialismo luso em África.

Vamos resumir o conteúdo desse artigo pioneiro estampado sob pseudónimo na Présence Africaine. A ideia lusotropicalista partiria do dogma de que os portugueses brancos se misturariam espontaneamente à vida tropical e praticariam largamente a mestiçagem, no que revelariam uma espécie de "generosidade própria da raça e do carácter dos portugueses" (7). Por outro lado, segundo Marcelo Caetano-teorizador salazarista oriundo do Integralismo Lusitano, pouco sensível ao lusotropicalismo freyriano e, sem dúvida, um dos colonialistas portugueses mais tingidos de racismo, como se pode constatar no seu estudo Os Nativos na Economia Africana (Coimbra, 1954) -, entre os tópicos fundamentais da administração colonial lusa achava-se a "assimilação espiritual", o que Pinto de Andrade se esforça por negar, uma vez que não descortinava onde estivesse o alegado respeito pela natureza dos povos colonizados no acto mesmo de lhes comunicar a fé cristã, pelo que não se coibe de comparar esta dita "assimilação espiritual" ao apartheid do dr. Malan (8). Para desmentir a pretensa assimilação dos povos autóctones das colónias portuguesas, Pinto de Andrade socorre-se do censo populacional de 1955 em Moçambique, observando que, numa população total de 5.732.317 habitantes, seriam europeus 18.213 (portugueses: 15.599), chineses 1.613, indianos 12.630, mestiços 12.630 e nativos "não civilizados" ou "indígenas" 5.640.363, restando ainda os nativos ditos "civilizados" ou "assimilados": apenas 4.349.

A crueza destes números oficiais desmentia a tão apregoada assimilação ou mestiçagem, e deles se podia concluir que a exploração enconómica daquela colónia lusa na África oriental repousava essencialmente nos tais 5.640.363 nativos negros "paralisados por um estatuto particular" (9). A tão decantada assimilação era, assim, praticada a uma escala mínima. Na mesma altura, sublinha Andrade, os dados populacionais das demais colónias portuguesas em África mostravam a mesma rea- lidade de uma ínfima assimilação. Na Guiné-Bissau, por exemplo, os assimilados eram 1.478 em 510.777 habitantes, e em Angola, se a população toral era de 4.145.266 habitantes, os negros seriam 4.036.687 e os assimilados apenas 30.089. As estatísticas oficiais demonstravam, deste modo, a debilidade do fenómeno da mestiçagem. E se, em Angola, de 1940 a 1950 , a população branca aumentara $79 \%$, a indígena crescera apenas $10 \%$ (10).

A teoria colonizadora portuguesa do "Estado Novo" salazarista basear-se-ia na doutrinação de Freyre, bastando alargar para a presença lusa em África o que o pernambucano dissera da colonização lusa no Brasil. A viagem de Freyre pelo império português em África (1951-52) inscrevera-se precisamente no quadro dessa "mistificação colonial moderna" (11). Para Freyre, na Casa Grande e Senzala (1933), dois séculos de presença colonizadora lusa no Brasil teriam sido um sucesso baseado na especial aptidão lusa para se adaptar aos trópicos, alicerçando-se o saber luso na mobilidade, na miscibilidade e na facilidade com que o português se aclimatara ao mundo tropical, de modo que esse processo, no seu conjunto, podia ser descrito como um equilíbrio entre antagonismos: antagonismos de civilização e de economia, entre homem europeu e homem africano, entre o africano e o indígena, além de tantos outros pares antagónicos cujas tensões dialécticas se logrou superar. Mas o antagonismo dominador de todos os demais era aquele que se travara entre o senhor e o escravo. Este antagonismo, como os demais, teve também maneiras de ser amortecido, harmonizado através de forças de confraternização e de mobilidade vertical, próprias do caso brasileiro, como a miscigenação e a dispersão das heranças, o acesso dos mestiços e dos filhos naturais aos altos cargos, o "cristianismo lírico à portuguesa", a tolerância moral e a hospitalidade em relação aos estrangeiros. Tudo isto fora dito por Freyre, nos começos da década de 30, em prol do esforço colonizador luso no trópico brasileiro, pretendendo-se desta maneira valorizar positivamente a atitude do colo- 
no português em terras de Vera Cruz, mostrando a sua cepa humanitária em relação a outros grupos étnicos com os quais estabeleceu contacto. Daí, também, a criação de uma sociedade colonial mestiça no Brasil colonial, em larga medida baseada na sexualidade, a qual Freyre acentua grandemente na sua análise, com algum desdém pelos dados económicos e políticos da análise histórica. Assim se evitava considerar o funcionamento do aparelho colonial como sendo, antes de mais, "uma empresa de exploração económica dirigida por um poder político", enfatiza Andrade (12). Compreende-se que o marxismo da análise de Andrade chocasse com as considerações transmateriais da focagem sociológica de Freyre, importante problema epistemológico que agora não vamos considerar.

Na sua réplica a Freyre, Andrade começa por sublinhar que, no Brasil, existiu de facto a mestiçagem apontada, não por causa de considerações morais ou de uma visão política mas por uma razão muito simples: o número reduzido de mulheres brancas (13). Desde 1940 que, no seu livro $O$ Mundo que o Português Criou, Freyre iniciava a sua transposição da explicação genética do Brasil para o caso da África portuguesa, apontando o conjunto de territórios lusófonos de Portugal, Açores, Madeira, África lusa, Índia portuguesa, Cabo Verde e Brasil como uma unidade de sentimento e de cultura. O leimotiv lusotropicalista estava dado, e a viagem às colónias lusas a convite do governo de Salazar, em 1951-52, seria a ocasião para rever, actualizar e ampliar a sua nova visão lusotropicalista de um imenso Portugal transcontinental e multirracial, o que se exprimira em especial nos livros Um Brasileiro em Terras Portuguesas e Aventura e Rotina; outros estudos seriam mais tarde editados pelo próprio governo luso, homenageando assim o papa do lusotropicalismo, tornado filosofia oficial do colonialismo português. Tudo repousava na suposta existência, diz o escritor angolano, dessa "unidade de sentimento e de cultura" em todos os países tropicais colonizados pelos portugueses, sob o seu domínio, unidade que teria resultado, segundo o pernambucano, dos pressupostos próprios da colonização lusa: o povo português seria “o mais cristão dos colonizadores modernos nas suas relações com as gentes ditas inferiores, o mais transbordante de simpatia" (14). Pergunta então Pinto de Andrade por que é que o tráfico negreiro praticado pelos lusos não encontrou qualquer objecção vinda desse mesmo cristianismo que diziam praticar, ou o trabalhoforçado em Angola, Guiné, S.Tomé e Moçambique (15).

Crendo na aptidão natural do colonoluso para viver nos trópicos e a tomar ali mulher de cor, Freyre não lograva porém explicar a questão colonial essencial, uma vez que, como insiste Andrade, não houve afinal uma cultura portuguesa nos trópicos africanos observando-se antes a destruição sistemática das culturas indígenas pela dominação colonial portuguesa (16). Como o sublinhara também André Julien na sua Histoire de l'Afrique (Paris, 1955), citada por Andrade, o que se observara na África portuguesa não fora a mestiçagem mas antes o racismo, uma vez que o estatuto do assimilado exigia que este só podia ser considerado tal se tivesse frequentado uma escola secundária ou comercial e falasse correntemente o português. Os contratados, por seu lado, prolongavam ali o velho trabalho escravo, o que Henrique Galvão - não citado aliás por Pinto de Andrade - tivera a coragem de informar a Assembleia Nacional salazarista desde 1947 (17), iniciando com esse acto destemido a sua própria queda política, aquela que o levaria à prisão, à fuga para o estrangeiro, ao exílio no Brasil e aos actos de guerrilha como o assalto e captura do paquete Santa Maria, nas Caraíbas, em 1961, poucos dias antes da guerra estalar em Angola...

Citando o estudioso francês acima referido, Andrade lembrava: "Não existe problema indígena nas colónias portuguesas na medida em que os negros são mantidos num estado próximo da servidão" (18). Se a lusotropicalidade não explicava inteiramente a formação e a originalidade do Brasil, ela seria ainda mais falsa quando transposta para os casos dos países africanos

\footnotetext{
12 ldem, ibidem, p. 27

13 ldem, ibidem, p. 28

14 Freyre apud Andrade, art cit p. 28. Mais adiante, Andrad cita uma passagem do livro Um Brasileiro em Terras Portugue sas (1952), na qual Freyre garantia que o português arabizado na base, teria a predisposição para as aventas amorosas sob o signo da "Vénus morena", sendo por isso menos imperialmente europeu que os outros, "juntando gos motivos económicos, religiosos e políticos da expansão ess gosto lausente em outros europeus) de viver, amar e procria crianças nos trópicos" (apud M. P. Andrade, op. cit., p. 30

15 Andrade, op. cit., p. 28. 16 Idem, ibidem, pp. 28-9.

17 Cf. H. Galvão, Assalto ao "Santa Maria" Lisboa Ediç̃es Delfos, 1974, pp. 87-106.

18 A. Julien apud Andrade, ar cit., p. 29
} 
colonizados pelos lusos, sublinha Andrade (19). Em suma, concluía Andrade, “sob a pena brilhantemente superficial" do sociólogo brasileiro, podia-se concluir que o lusotropicalismo seria, ao mesmo tempo, um conceito, uma teoria, um sistema e um método de colonização, consistindo na vocação congénita do português para ser atraído pela mulher de cor nas suas relações sexuais; o desinteresse do português em relação à exploração económica dos trópicos; a manutenção de relações sociais com os habitantes dos países tropicais no sentido da mobilidade vertical na vida social e política, donde o corolário: uma parte da Ásia, da África e da América dominada por um pequeno número de portugueses que trariam no sangue a herança tropical de cruzamentos com mouros, revelando a marca de uma unidade de sentimento e de cultura que se chamaria "civilização lusotropical” (20). Em 1951, o governo de Salazar convidara Freyre a fazer uma visita às colónias portuguesas no mundo, viagem donde resultou o livro Aventura e Rotina (Rio, 1953). Esta obra viria comprovar ainda mais a estima que esse império colonial e a nossa política africana mereciam ao sociólogo pernambucano. A terminar, Pinto de Andrade nega que tivesse havido na África colonizada pelos portugueses um "complexo cultural" lusotropical, um casamento de duas culturas, um contacto desejável entre duas culturas diferentes - a europeia e a africana -, mas apenas uma relação entre uma cultura dominadora e uma cultura dominada, donde resultava que o apregoado lusotropicalismo de Freyre seria uma "mistificação", uma teorização viciada na base, uma "falsa interpretação da génese da expansão marítima portuguesa" (21). A interpretação de Vitorino Magalhães Godinho no seu livro A Expansão Quatrocentista Portuguesa parece-lhe mais adequada: Portugal teria criado um império comercial cuja alma eram as especiarias, o fundamento o saque, os nervos os canhões (22). Daí a conlusão final do angolano: o lusotropicalismo era uma "impostura velada” (23). Lembremos que a crítica de Mário Pinto de Andrade a Freyre fora escrita seis anos antes de começar a rebelião angolana. Já a de Amílcar Cabral viria em plena fase da luta de guerrilha contra o colonialismo luso. Prefaciando um livro de Basil Davidson sobre a guerra de libertação da Guiné-Bissau-Révolution en Afrique. La Libération de la Guinée Portugaise ( $\mathrm{Pa}-$ ris, 1969) -, Cabral redigia, em outubro de 1968, um curto texto onde, começando por deplorar o "muro de silêncio"(24) que os colonialistas lusos tinham conseguido erguer em relação aos povos que guerreavam as tropas europeias, lembrava o mito do lusotropicalismo nestes termos:

"Introduzindo à pressa alterações na Constituição portuguesa com o fim de escapar à obrigação das Nações Unidas, o colonialismo fascista de Portugal conseguiu, além disso, cortar todas as possibilidades de informação não-oficial acerca das suas 'províncias ultramarinas’. Uma importante máquina de propaganda foi posta a funcionar com o fim de convencer a opinião internacional de que os nossos povos viviam no melhor dos mundos, que éramos portugueses felicíssimos e cujo único sofrimento seria a nostalgia da branca mãe-pátria separada pela fatalidade geográfica. Todo um mito foi construído. E, como em todos os mitos, sobretudo quando se referem ao domínio e exploração dos povos, não faltam 'homens de ciência' entre os quais um sociólogo conhecido, para lhe dar uma base teórica: olusotropicalismo. Gilberto Freyre, confundindo, talvez involuntariamente, realidades (ou necessidades) biológicas e realidades socio-económicas (históricas), fizera de todos nós, povos das colóniasprovíncias portuguesas, os felizes habitantes do paraíso lusotropical” (25).

\section{FREYRE EM CABO VERDE}

Freyre parte para as colónias lusas em outubro de 1951, depois de ter estado alguns meses em Portugal continental: começa por visitar a Guiné-Bissau, vai depois a Cabo Verde (visita as ilhas do Sal, 
Santiago e São Vicente), São Tomé e Príncipe, Angola, Goa (dezembro) e, em meados de janeiro de 1952, Moçambique. Passa também pela Madeira, tendo ainda o vagar de percorrer todo o Portugal continental de lés a lés, estando com inúmeros intelectuais portugueses (António Sérgio, Nuno Simões, Manuel Mendes, Aquilino Ribeiro, Vitorino Nemésio, Manuel Múrias, etc.), tanto afectos como desafectos à Ditadura vigente. Desta visita vamos sublinhar aquela que fez ao arquipélago de Cabo Verde, na medida em que, como melhor veremos adiante, uma natural disposição "lusotropicalista" destas ilhas deveria ter entusiasmado o mestre de Santo António de Apipucos como ilustração das suas teses sobre a formação da sociedade mestiça do Brasil. A resposta crítica que esta sua visita mereceu a um ilhéu, o intelectual caboverdiano Baltasar Lopes, completará o exame deste detalhe crucial da via imperial portuguesa seguida pelo sociólogo recifense.

Qual o papel da sociedade mestiça de Cabo Verde na formulação freyriana? Tendo visitado, como convidado oficial do governo português da altura - sendo o almirante Manuel Maria Sarmento Rodrigues o ministro das Colónias (1950-55) que lhe dirigiu o convite para essa viagem oficiosíssima-, o arquipélago caboverdiano em começos da década de 50 - mais exactamente em outubro de 1951, aliás numa altura em que o campo de concentração do Tarrafal, na ilha de Santiago, ainda funcionava, pois só seria mandado encerrar em 1954, para reabrir as portas quando se iniciassem as guerras coloniais... -, Freyre começa por notar, no livro escrito em finais de 1952, e publicado no Brasil em 1953, e em Portugal numa edição sem data, provavelmente desse mesmo ano ou do ano seguinte - Aventura e Rotina. Sugestões de uma Viagem à Procura das Constantes Portuguesas de Carácter e Acção (26) -, que Cabo Verde é uma espécie de Ceará africano desgarrado no meio do Atlântico (27), um país pirandelianamente à procura de um destino (28), ou uma Martinica afroportuguesa (29) onde os colonizadores ensaiaram as primeiras grandes miscigenações entre italianos, judeus, portugueses e negros trazidos da Guiné, ao mesmo tempo que experimentavam um tipo de arquitectura que transplantariam para o Brasil, e praticaram o cultivo da cana-de-açúcar que seria o essencial do mundo lusobrasileiro da casa grande e senzala, da cultura e da economia do Brasil colonial, assim como esboçaram ali a primeira criação do gado nos trópicos (30).

Num outro livro, espécie de apostila à sua viagem de 1951 pelas colónias portuguesas, Freyre incluía duas páginas mais sobre Cabo Verde, para repetir que o arquipélago the lembrava o Ceará, que ali um brasileiro se sentia em casa e que aquelas águas eram "quase as do Nordeste do Brasil” (31). E sublinhava: "Em Cabo Verde, o Portugal e a África encontraram-se em dias remotos, em antecipação do encontro de culturas que no Brasil se tornaria a maior aventura de miscigenação nos trópicos: a de maior amplitude nas suas consequências éticas e nos seus efeitos estéticos" (32). Por outras palavras, seria de esperar que o lusotropicalismo, a chave sociológica e histórica usada para interpretar a génese do Brasil, fosse aproveitado por Freyre para valorizar o especial microcosmo exemplar deste "arquipélago-escala" (como lhe chamara Jaime Cortesão). Mas não foi isso o que sucedeu, como melhor veremos em seguida. O que mais impressionou o sociólogo do Recife é que aqui, nesta terra onde só seria europeu o que fosse oficial - ou seja, edifícios, ritos administrativos, fala dos burocratas, modos de trajar, etc. (33) , a população nativa conseguiu produzir um dialecto próprio, que Freyre confessava repugnar-lhe: "Do mesmo modo que me repugna o dialecto cabo-verdiano, agradame ouvir a gente de Cabo Verde falar o português, à sua maneira, que é a maneira tropical, brasileira..."(34) -, o que não sucedeu no imenso Brasil (35); o exotismo caboverdiano começa, pois, no crioulo. Daí a maior presença da africanidade nestas ilhas do que noutras colónias lusas, já que os naturais daqui não se deixaram absorver ou dissolver na cultura dos portugueses, como aconteceu nas demais colónias que
26 Gilberto Freyre, Aventura e Ro tina. Sugestões de uma Viagen a Procura das Constantes Por tuguesas de Carácter e Acção Lisboa, Livros do Brasil, s.d. 455 pp. A la ed. desta obra saiu no Brasil, em 1953, editada por José Olympio, Rio de Janeiro.

27 G.Freyre, op. cit., p. 237

28 ldem, ibidem, pp. 237-8

29 ldem, ibidem, p. 240.

30 ldem, ibidem, p. 239.

31 G. Freyre, Um Brasileiro em Terras Portuguesas, Lisboa, Livros do Brasil, s.d, pp. 171 e 170 respectivamente.

32 G.Freyre, op.cit., p. 171

33 G. Freyre, Aventura e Rotina p. 240

34 ldem, ibidem, p. 248.

35 Idem, ibidem, loc.cit. 
36 ldem, ibidem, p. 240

37 ldem, ibidem, pp. 24 1-3.

38 Sobre Salazar, cf. G. Freyre, Aventura e Rotina, pp. 21 segs., 60 e segs., 165 e 182 e segs

39 Veja-se Pablo Neruda, poema "Los Presidios", in Las Uvas ye Viento, Barcelona, Seix Barral 1976, p. 257. Sobre este campo de concentração veja-se nossa História Contemporânea de Portugal, tomo I do "Estado Novo" Lisboa, Amigos do vro, 1986, pp. 220-35

40 G. Freyre, Aventura..., p. 22

41 Idem, ibidem, loc.cit.

42 ldem, ibidem, p. 23.

43 Idem, ibidem, p. 60.

44 Idem, ibidem, pp. 164 e segs

45 Idem, ibidem, p. 164

46 Idem, ibidem, loc.cit.

47 Idem, ibidem.

48 Idem, ibidem, p. 165

49 ldem, ibidem, loc.cit.

50 ldem, ibidem.

51 Idem, ibidem, p. 182

52 ldem, ibidem, p. 183

53 ldem, ibidem, loc.cit.

54 ldem, ibidem, p. 182

$55 \mathrm{ldem}$, ibidem, p. 183

56 ldem, ibidem, pp. 245-6.

57 ldem, ibidem, p. 246

58 ldem, ibidem, loc.cit.

59 ldem, ibidem, p. 247

$60 \mathrm{ldem}$, ibidem, pp. 250-1

61 Idem, ibidem, p. 250 os lusos ocuparam. Para Freyre, este fenómeno ocorria sobretudo da Ilha de Santiago (36). Adiante veremos como esta interpretação freyriana teve firmes críticos em autores caboverdianos como Baltasar Lopes e outros.

Quanto ao lusotropicalismo político de Cabo Verde, este era aquele que Freyre acarinhava, uma vez que a autoridade do governador seria toda patriarcal e paternal, já que Sua Excelência se misturava sem problemas com o povo, ia aos seus bailes, sem escolta, numa espantosa "confraternização de governantes brancos com governados mestiços" (37). Não admira, aliás, que a figura do ditador português o fascinasse, a ponto de dedicar ao "Grão Doutor" Salazar diversas páginas de insofismável apreço (38), do mesmo modo que freudianamente se esqueceria de reparar no campo da morte do Tarrafal, aliás celebrado pelo poeta chileno Neruda (39) como uma das nódoas mais evidentes da nossa ditadura... Detenhamo-nos no retrato de Salazar feito pelo seu admirador brasileiro.

Freyre diz ter sido recebido por Salazar como um profesor recebe um colega. Diz dele: "É o homem mais ágil de olhar, mais agudamente vigilante, mais dialecticamente atento, ou que ouve, do que tenho conhecido" (40). A sua palavra não teria eloquência, sendo monótona e nítida, fazendo-lhe lembrar um inimigo dele, António Sérgio (41). Seja como for, Salazar seria "um dos maiores portugueses de todos os tempos". Havia nele uma certa "dignidade episcopal", com alguma coisa de "semita" (42). A voz era suave. Tinha algo de um défroqué, "psicologicamente défroqué" (43), esclarece. Se fosse português, Freyre garante que apoiaria o regime salazarista (44). Desagradou-lhe, porém, o excesso de "policialismo" do regime (45). Mas acha que o nosso ditador defende os portugueses do "excesso do poder da vulgaridade sobre a massa eleitoral" e dos excessos do dinheiro (46). Acha porém a censura humilhante, talvez mesmo desnecessária (47). O regime, em suma, parece-lhe "um raro exemplo de normalidade em contraste com a si- tuação anormalíssima na Europa e na América" (48). Mas garante que o policiamento é mais "feito na aparência que na realidade" (49). (Tendo visitado Portugal em 1923, 1936, 1937, 1948 e 1951, espanta uma declaração sua deste teor!). Portugal não estaria, pois, em "situação de vergonhosa inferioridade com relação àquelas brilhantes democracias políticas de hoje" (50). A casa pobre de Salazar em Santa Comba lembrava-lhe a de Herculano em Vale de Lobos (51). Salazar seria, pois, “um grande homem de governo que se delicia em ser apenas eminência parda ou cinzenta dos continuadores dos reis" (52). Não dá nas vistas, ao contrário dos Peróns, Hitlers ou Francos, "quase sem sair de Portugal"(53), quase sem ser visto pelos seus compatriotas (54), sem mulher nem filhos, sem sair do seu gabinete (55)...

A literatura local interessou Freyre: cita Jorge Barbosa, Baltasar Lopes - então a ensinar no Brasil, futuro autor de uma brochura criticando justamente a interpretação freyriana da sua terra natal -e José Lopes (que era, aliás, vice-consul do Brasil em Cabo Verde) (56). Lembra que José Lopes colaborara no velho Almanaque de Lembranças Luso-Brasileiro, "almanaque precursor de uma cultura luso-tropical" (57), almanaque começado nos meados do séc. XIX, e que era lido de Goa ao Brasil, passando pelas colónias portuguesas em África. Muitos destes escritores se sentiam mais próximos do Brasil do que de Portugal, nota o pernambucano (58). Até os meninos que se banhavam afoitamente nas águas perigosas das ilhas lhe lembravam os "capitães de areia” de Jorge Amado (59).

O que mais deplorava Freyre em Cabo Verde era a ausência de arte popular (60). Nada lhe ficara, no artesanato, das suas raízes africanas, ausência deplorável até porque privava os ilhéus de uma fonte de receita como a da Madeira ou de São Tomé e Príncipe (61). Daí que este cantor do lusotropicalismo sugira que se avigorasse antes em Cabo Verde a cultura europeia, já que a africana lhe parecia incapaz de transcender a “instabilidade cultural” pró- 
pria dos nativos do arquipélago: "Para corrigir-se este estado de instabilidade de incaracterização é que me parece necessário um revigoramento da cultura - cultura em sentido sociológico - europeia" (62). Uma evidente incapacidade de se aperceber da identidade caboverdiana ou até de a aceitar como possível ou mesmo inevitável - ressalta desta passagem do sociólogo pernambucano, inexplicavelmente míope neste lance. Compreende-se que os intelectuais caboverdianos, que desde 1936 vinham traçando uma via original para a sua peculiaridade nativa na revista Claridade (63), não tivessem apreciado muito esta interpretação do brasileiro. Sublinhe-se, a propósito, que nesta obra de 1953, além de uma patente intenção de glorificar o regime e a pessoa de Salazar, já acima referida, Gilberto Freyre, em paradoxal contradição com o seu passado de inimigo da ditadura de Vargas, nunca se mostrou inclinado a aceitar a hipótese da independência das colónias portuguesas em África. Neste aspecto, este volumoso livro de notas de viagem ao “império" lusitano em Áfricabem como o seu já referido suplemento, Um Brasileiro em Terras Portuguesas não deixa de constituir um deplorável instrumento de propaganda em prol de um regime que, pouco tempo volvido sobre a sua edição, iniciaria nas suas colónias um longo, doloroso e criminoso ciclo de guerras que se arrastaria até 1974, engrenagem de morticínio e sofrimento a que, contudo, o arquipélago de Cabo Verde escaparia...

O dialecto crioulo, portanto, para Gilberto Freyre, contribuiria para a instabilidade cultural do cabo-verdiano (64). A única excepção a esta lacuna encontrou-a no Sal, na música: a morna, de cuja semelhança com a música popular brasileira ele se apercebera desde os tempos dos carnavais no Recife (65). A única realidade pujante estava na literatura lusotropical de Cabo Verde, a mais viva do género depois da do Brasil, garante (66). Eis, pois, sucintamente gizada, a visão que de Cabo Verde teve Freyre no início da década de 50.

\section{A CRITICA DE UM CABOVERDIANO A GILBERTO FREYRE: BALTASAR LOPES}

Debrucemo-nos agora sobre a resposta que o destacado intelectual e estudioso de Cabo Verde deu, em 1956, às considerações feitas sobre o arquipélago por Gilberto Freyre. Aos microfones de Rádio Barlavento, de São Vicente, de 12 de maio a 23 de junho de 1956, Baltasar Lopes pronunciou uma série de seis palestras que iria publicar no mensário Cabo Verde (de 1 de setembro a 1 de novembro de 1956) e, por fim, reunir em folheto, nesse mesmo ano, sob o título de Cabo Verde Visto por Gilberto Freyre (67). Lembrando quanto os caboverdianos estimavam a obra de Freyre - assim como a do também antropólogo e folclorista brasileiro Artur Ramos (190349), o autor de obras como O Negro Brasileiro (1935) e A Aculturação Negra no Brasil (1942) -, Baltasar Lopes recorda deste jeito quanto o entusiasmou a chegada do ilustre sociólogo às ilhas: "Enfim, Gilberto Freyre veio. Chegou, viu, interpretou. Porém, na minha ignorância, mas também na minha suspeita dos métodos da ciência que o mestre brasileiro cultiva com tanto brilho, poderia ele dar das nossas ilhas uma interpretação não eivada de pressa jornalística, no tão pequeno espaço de tempo e na pobreza de contactos com que teve, tant bien que mal, de receber um vislumbre da nossa vida?" (Cabo Verde Visto por Gilberto Freyre) (68). E logo comenta que Freyre apenas "arranhou o litoral" de três das ilhas caboverdianas - Santiago, São Vicente e Sal (69) - e que, na segunda, se ficara pela zona urbana da ilha (70). Viu "Ulisses (Jorge Karantonis), o Judeu exógeno (o nosso conhecidíssimo e, há tanto tempo, tropicalíssimo Schonfield), conheceu o sósia (fisionómico) de Mário Pinto de Andrade e (cultural) de Pixinguinha", tendendo para a generalização simples e os pormenores insignificativos (71). Do batuque, por exemplo, viu apenas a "sobrevi-

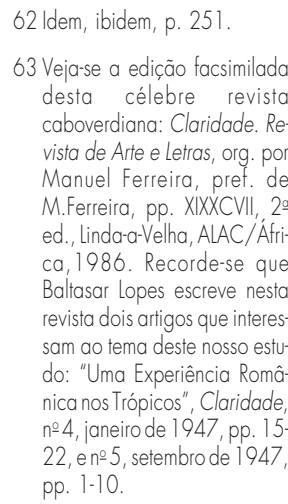

67 Baltasar Lopes da Silva, Cabo Verde Visto por Gillberto Freyre. Apontamentos Lidos aos Microfones de Rádio Barlavento, Imprensa Nacional, Divisão de Propaganda, 1956, 52 pp. separata de Cabo Verde. Boletim de Propaganda e In formação, Praia, Imprensa Nacional, n-s 84-6, 1 de se tembro a 1 de novembro de 1956). Recordemos que Baltasar Lopes da Silva (1907. 89), nascido em Vila da Ribeira Brava, se formou em Filologia Românica na Fac. de Letras de Lisboa, desempe nhando, em 1956, as funções de reitor do liceu Gil Eanes em S. Vicente. O seu célebre ro mance Chiquinho fora publicado em 1947

68 B. Lopes, op.cit., p.7

69 ldem, ibidem, loc.cit.

70 ldem, ibidem, p. 8

71 ldem, ibidem, loc.cit. 
72 ldem, ibidem, p. 7

$73 \bigcirc$ famoso veleiro Areias - ou Senhor das Areias lou ainda Senhora das Areias) - era um ugre com motor e vela, construído em Espanha, em data incerta, e reconstruído em Aveiro em 1943; não se sabe quando chegou a Cabo Verde. Sabe-s que em 1945 se denominava Senhora das Areias, tendo passado depois a Senhor das $A$ reias (cf. Boletim Oficial, no 18 desse ano). Em dezembro de 1968 foi desmantelado. O seja, depois da visita de Freyre, ainda o heróico Areias viajou mais dezassete anos... O Areias toi objecto de uma emissão de moedas caboverdianas, juntamente com outros barcos do arquipélago (v.g. Madalan Belmira, Novas de Alegria, etc.| no valor de 50 escudos, em liga de aço niquelado, com peso de 7,40 gr e 28 mm de diâmetro moeda ainda corrente em Cabo Verde, e editada pelo Banco de Cabo Verde numa colecção de moedas, com reproduções notícias sobre os barcos contemplados.

74 B. Lopes, op.cit., p. 9

75 Idem, ibidem, pp. 9-10

76 Idem, ibidem, p. 16.

77 Idem, ibidem, p. 14.

78 Idem, ibidem, loc.cit.

79 ldem, ibidem, p. 18.

80 ldem, ibidem, p. 15.

81 ldem, ibidem, p. 14.

82 ldem, ibidem, p. 18

83 Idem, ibidem, loc.cit.

84 Idem, ibidem, p. 39.

85 Idem, ibidem, p. 21.

86 Idem, ibidem, p. 22.

87 ldem, ibidem, loc.cit.

88 ldem, ibidem.

89 ldem, ibidem, p. 26

90 ldem, ibidem, p. 27.

91 Baltasar Lopes, O Dialecto Crioulo de Cabo Verde, Lisboa, Imprensa Nacional/Junta das Missões Geográficas e de Investigações do Ultramar, Centro de Estudos Políiticos e Sociais, 1957, 391 pp.; reed. em facsimile em 1984.

92 B.Lopes, Cabo Verde Visto por G. Freyre, op. cit.

93 Idem, ibidem, pp. 30-1

94 Idem, ibidem, p. 30.

95 Idem, ibidem, p. 35.

96 ldem, ibidem, p. 33.

97 Idem, ibidem.

98 ldem, ibidem, pp. 48-9. vência da velha África" (72), troçou até do velhíssimo veleiro Areias (73) que o levou até ao Sal (74), o que é um exemplo raro de sociólogo que não valoriza o arcaismo no seu contexto vital, ecológico (75), interpretou o negro caboverdiano à luz do velho livro de Archibald Lyall (Black and White make Brown, 1938) (76), comparou indevidamente as Antilhas ao arquipélago caboverdiano (77), concluiu que o "caboverdiano é mais africano do que português" (78), viu em excesso a presença ou sobrevivência de África na vida e na psique caboverdiana, como, por exemplo, na religião sobrevalorizou a presença dos cultos africanos quando aquela seria, afinal, insignificante (79).

E conclui: "ponho as minhas dúvidas ao africanismo tamboriado por Gilberto Freyre" (80). E espanta-se: "Pela cabeça de quem, medianamente informado das coisas de Cabo Verde, é que passa que o caboverdianoé mais africano do que português?" (81). Nos cultos cristãos, por exemplo, Freyre achou africanismo, duvidando Baltasar Lopes que realmente houvesse neles “africanismo essencial”" (82), à excepção das tabancas da ilha de Santiago (83). Discorda ainda da apreciação freyriana quanto à alegada esterilidade cultural dos caboverdianos, atribuindo-a a uma ilusão resultante do "grau avançado, no sentido europeu, a que as ilhas chegaram" (84). Discorda de que houvesse entre o português e o caboverdiano uma disputa entre a entidade social de Cabo Verde e "o todo português de que fazemos parte"'(85). Para Baltasar Lopes - e nisto muito próximo das teses oficiais do colonialismo luso em África -, "na conduta do caboverdiano não é a África a força dominante" (86). Dizendose isento de um "ufanismo" caboverdiano (87), Baltasar Lopes garante que não encontrou "um caso em que se tenha imposto como espécime caracterizado da presença dominante de África" (88). Quanto à deficiência de Cabo Verde em relação ao artesanato, à arte decorativa popular, reconhece que estes faziam falta, embora houvesse outras formas de manifestação do génio popular como "o folclore novelístico; o folclore dos provérbios e das adivinhas; a música popular e a sua instrumentação; as festas populares [...] e, a dominar tudo, o facto importantíssimo de que o arquipélago dispõe de um instrumento de comunicação, o crioulo" (89) - esse mesmo crioulo que Freyre dizia repugnar-lhe...Perguntava Baltasar Lopes: "E a um cientista é reconhecido o direito de sentir repugnância pela matéria observada?[...]. Confesso não compreender a alergia de Gilbero Freyre em relação ao crioulo" (90).

Assim, o crioulo, como seria de esperar por parte do autor de $O$ Dialeto Crioulo de Cabo Verde (91), desperta a crítica de Baltasar Lopes. Se Freyre elogiava tanto o tal "mundo que o português criou" - título, aliás, de um livro seu -, como se compreende a sua repugnância por esta forma da língua engendrada pelo português nos trópicos? Seja como for, o crioulo "é a criação mais perene nestas ilhas. Tudo pode desaparecer ou modificar-se no arquipélago: conduta, trajos, mobilidades das classes; se não ocorrer um cataclismo, físico ou social [...], podemos ter a certeza de que, para me citar a mim mesmo, o crioulo está radicado no solo destas ilhas como o próprio indivíduo" (92). Baltasar Lopes critica ainda em Freyre a desvalorização literária e funcional do crioulo, acusando-o de despiciência e, indirectamente, de simplismo e falta de humildade (93). O crioulo, sendo a "respiração do povo que o criou" (94), está definitivamente integrado "no corpo de ideias e de sentimentos que formam a nossa personalidade regional" (95). Coexiste com o português, nobilitando-se "em contacto com a língua mãe, não se dissolve nela; pelo contrário, mantém intacta a sua personalidade" (96). E sublinha: "Rigorosamente, somos todos bilingues" (97).

Também a desvalorização da culinária insular incomoda Baltasar Lopes, contrapondo às considerações depreciativas de Freyre acerca da alimentação e cozinha caboverdianas as qualidades da cachupa, xerém, cuscus, brinhola, batanca, etc. (98). Eis, em suma, o essencial da resposta de Baltasar Lopes a Gilberto Freyre, decep- 
ção resumida na frase: “O Messias desiludiu-nos" (99).

Alguns anos depois, num colóquio cujas comunicações seriam publicadas em livro em 1959 (100), alguns reparos se ouviriam ainda aos textos de Freyre na sua Aventura e Rotina. Por exemplo, Manuel Lopes, no seu ensaio "Reflexões sobre a Literatura Caboverdiana ou a Literatura nos Meios Pequenos" (101), sem se debruçar explicitamente sobre o livro do sociólogo brasileiro e a sua viagem de outubro de 1951 a Cabo Verde, fazia algumas reflexões que podemos tomar como crítica mais ou menos directa àquelas observações do viajante brasílico. Louvando a acção da revista Claridade - nunca mencionada por Freyre -, diz que esta, secundada pelo boletim Cabo Verde, tinha trazido consigo alguns torrões de crioulo agarrados à raiz (102), lembrando que a própria revista Presença definira o contributo de Claridade em duas palavras: regionalismo e universalidade (103).

Logo adiante, um extenso artigo do poeta Gabriel Mariano, intitulado "Do Funco ao Sobrado ou o 'Mundo' que o o Mulato Criou" (104), fazia uma refutação indirecta de Gilberto Freyre, ainda que não o mencionando. Por exemplo, sublinhava algo em que Freyre não reparara (ou não quisera reparar?): que "em Cabo Verde, diferentemente do que sucedeu nos outros territórios colonizados por portugueses, foram os negros e os mulatos os responsáveis directos na estruturação da sua sociedade" (105). Esta tónica seria dominante na análise de Mariano quanto ao “especialíssimo caso caboverdiano" (106), o que teria permitido que, no arquipélago, uma forma diferente e própria de lusotropicalismo florescesse: "o processo aculturativo desabrochou no florescimento de expressões novas de cultura, mestiças [...]", de modo que no arquipélago puderam "o negro e o mulato apropriar-se de elementos da civilização europeia e sentilos como seus próprios, interiorizando-os e despojando-os das suas particularidades contingentes ou meramente específicas do europeu" (107). Estaria Gabriel Mariano a pensar em Freyre e no seu Aventura e Ro- tina quando redigiu estas linhas? É possível. Mais adiante, outra observação deste autor merece ser sublinhada: "Em Cabo Verde [...] o mulato adquiriu desde cedo grande liberdade de movimentos e teria sido ele quem realizou em Cabo Verde o papel que o português reinol desempenhou no Brasil. Isto é: ter-se-ia transferido para o mulato a condição de mestre, de líder na estruturação da sociedade caboverdiana" (108). Em suma, teria sido o funco - a habitação primitiva própria de Cabo Verde e não o sobrado "o laboratório exacto onde se produziu a síntese das culturas e a apropriação pelo negro e pelo mulato de elementos e expressões civilizacionais portugueses" (109).Um desses casos foi, evidentemente, o crioulo (110) como língua materna de Cabo Verde. Se, no Brasil, os crioulos desapareceram e ficou apenas o falar dos portugueses, em Cabo Verde triunfaria um crioulo persistente, transformado em instrumento de comunicação em todo o arquipélago, revelando-se, depois, veículo de criação literária. Em suma: "Contrariamente ao Brasil, o mulato pôde ser o mestre da sua sociedade" (111). Não deixa, por isso, de ser irónico que, ao prefaciar este conjunto de estudos, o prof. Jorge Dias tivesse garantido: “O caboverdiano constitui o caso mais perfeito de cultura lusotropical" (112).

Não sabemos se alguma vez Gilberto Freyre teria meditado nesta sua inexplicável gaffe de sociólogo e observador político acolhido com especial carinho pelo governo português, nesta viagem paga e amparada pela administração colonial da Ditadura lusa, a ponto de nunca se ter lembrado da existência, naquele arquipélago, de um atroz campo de concentração para inimigos do regime salazarista... Tendo estado em 1951 em Cabo Verde, ainda que por poucos dias, o arguto sociólogo recifense não se apercebeu de que tinha diante dos olhos um dos casos mais vívidos e pujantes daquele lusotropicalismo que ele enaltecera tanto, não só quanto ao Brasil mas ainda e aqui com alguma culpa política - quanto às demais colónias lusas em terras de África, no tal "mundo que o português criou" -

\footnotetext{
99 ldem, ibidem, p. 11

100 Colóquios Cabo-Verdianos Lisboa, Junta de Investigações do Ultramar/Centro de Estudos Políticose Sociais, 1959182 pp., pref. de Jorge Dias.

101 Colóquios..., pp. 1-22

102 ldem, ibidem, p. 20.

103 ldem, ibidem, loc.cit

104 Idem, ibidem, pp. 23-49.

105 Idem, ibidem, p. 30.

106 ldem, ibidem, p. 32.

107 ldem, ibidem, p. 33.

108 Idem, ibidem, p. 39

109 Idem, ibidem, loc. cit.

110 Idem, ibidem, p. 40

111 ldem, ibidem, pp. 40-1.

112 Idem, ibidem, p. XII.
} 
e que, poucos anos volvidos, forcejaria dolorosamente por se libertar do domínio português...Típico lapso resultante de um preconceito ou de um evidente parti-pris político? Mero daltonismo de viajante apressado...? Ainda que sendo brasileiro, não teria, afinal, Freyre sucumbido a uma ilusão muito eurocêntrica - a de supor que só haveria "verdadeiro" lusotropicalismo enquanto se mantivesse o domínio dos senhores brancos sobre negros e mulatos, mesmo numa sociedade tão intensamente mestiçada como a de Cabo Verde...? Ou não haveria ainda uma outra mais subtil e perversa origem deste seu evidente preconceito de sociólogo: a de partir do princípio que o arquipélago era demasiado africano para que se pudesse tomar como verdadeiramente "lusotropical"? Para quem quisera tão enfaticamente combater e anular uma visão eurocêntrica, branca, dos trópicos pervertidos pela cor e pela raça negra ou ameríndia - contra o "europeísmo ao mesmo tempo arrogante e céptico"( Um Brasileiro...) (113), em prol das "gentes amarelas, pardas, vermelhas, pretas, por meio de estudos comparados de sociologia das culturas, portadores de valores superiores e não apenas inferiores aos dos brancos e europeus" (114) -, tal perspectiva era, no mínimo, contraditória ou escandalosa.

O facto, ulteriormente verificado ainda em vida do próprio recifense, de que os caboverdianos não conheceriam intra muros uma guerra contra Portugal não lhe teria suscitado uma perplexidade geradora de interrogações que, mais do que nenhuma outra, pediam uma indagação de exegeta armado de lentes da sociologia e da história...?

Em suma, no tocante à visita de 1951 a Cabo Verde, Freyre foi posto em contacto com uma das mais conseguidas experiências de miscigenação física e cultural de todo o mundo colonial português, deparando-se assim com uma sociedade que lograra até criar o seu dialecto, realidade absolutamente anómala no resto do mundo que o português criara. Embora encontrando no arquipélago caboverdiano muitas das raízes que haveriam de frutificar no Brasil colo- nial desde o séc. XVI, Freyre não se entusiasmou com a especificidade - ou com a originalidade - da construção "lusotropical" ali encontrada. A própria originalidade ou especificidade identitária do arquipélago caboverdiano - identidade que transcendia os pressupostos da tal mítica civilização pluricontinental e multirracial - desconcertava-o e, de algum modo, desiludia-o, porventura frustrava as suas premissas de base. Por isso, em vez de aceitar e vitoriar a via caboverdiana dentro do modelo lusotropical, Freyre evita celebrála e até fez do crioulo uma das razões da "instalibilidade cultural" do arquipélago. As respostas que lhe deram posteriormente alguns intelectuais caboverdianos - de que examinámos aqui e agora tão só alguns exemplos frisantes - mostrariam como estava equivocado o sociólogo brasileiro, já então ao serviço da propaganda colonialista da Ditadura portuguesa, a cerca de dez anos de se iniciarem em África as guerras coloniais que Salazar - e depois Marcelo Caetano - haveriam de arrastar durante treze anos (mandando até reabrir em 1961 o campo de concentração do Tarrafal, encerrado em 1954), sem glória nem proveito para ninguém, tanto para colonizadores como para colonizados... Guerra africana que-deixemos a interrogação em aberto - arrastaria o arquipélago para uma deplorável centrifugação histórica e política que o afastaria de quaisquer outras formas democráticas e livres de caminho comum futuro para os povos caboverdiano e português. Guerra durante a qual os seus dirigentes africanos nunca deixaram de ver em Freyre - como Mário Pinto de Andrade o fizera em 1955, antes mesmo de o conflito começar - um evidente e consciente aliado da causa colonialista lusa, um teorizador ao serviço da política portuguesa, cujo alibi foi o lusotropicalismo, política responsável por uma guerra que seria, dentro do drama da Ditadura iniciada em 1926, um dos expoentes mais altos e mais cruelmente pertinazes do erro e da persistência nessa escolha erra$\mathrm{da}$ - a de negar aos povos de África a independência que estes pediam, a que estes tinham afinal pleno direito. 
As críticas às aventuras colonialistas de Freyre não se resumiram aos nomes acima evocados. Conviria lembrar que, no próprio Brasil, alguns intelectuais lembraram a condição de propagandista do regime ditatorial luso assumida pelo autor de Casa Grande e Senzala: fe-lo, por exemplo, a escritora Raquel de Queiroz, num artigo publicado no Cruzeiro, em abril de 1952 , no qual criticava o facto do seu compatriota nordestino ter aceito o convite do governo de Salazar; respondeu-lhe Freyre alegando que estivera, na sua visita, com intelectuais conhecidos pela sua hostilidade ao ditador luso... (115). Um português então exilado no Brasil, Tomás Ribeiro Colaço, escreveu no Correio da Manhã, do Rio, um artigo, intitulado "Carta a Gilberto Freyre”, deplorando que o nome do prestigiado sociólogo tivesse sido "fraudulentamente usado ao serviço daquele totalitarismo", o de Salazar (116). A verdade é que, desde então, a máquina de propaganda do regime português não mais deixaria de capitalizar em proveito da sua política colonial as posições de Freyre. Este passaria, aliás, a colaborar quinzenalmente no vespertino lisboeta Diário Popular, então dirigido por um salazarista dos quatro costados, antigo "camisa azul" das hostes hitlerófilas de Rolão Preto, Luís Forjaz Trigueiros, um íntimo do mestre de Santo António de Apipucos, e que mais tarde viveria exilado, depois da revolução democrática portuguesa de 1974, no Brasil (1975-78). Mas todos estes aspectos da polémica em torno das posições pró-colonialistas portuguesas de Freyre transcendem já o escopo deste artigo, cujo fito essencial foi tão só chamar a atenção para uma faceta menos prestigiante e menos conhecida - ou freudianamente mais activamente esquecida...-do pensamento e da acção profana do sociólogo recifense em causa, bem como para algumas das réplicas que lhe foram dirigidas por africanos.
115 Cf. Raquel de Queiroz, "Por
Terras de Além Mar", Cru-
zeiro, abril de 1952; e G.
Freyre, "Outros Pontos nos ii",
Cruzeiro, maio de 1952.
116 T. Ribeiro Colaço, "Carta a
Gilberto Freyre", Correio da
Manhã, Rio de Janeiro, 4-ll-
1952 . 